\title{
Duodenal Somatostatin-Producing Neuroendocrine Tumor
}

National Cancer Institute

\section{Source}

National Cancer Institute. Duodenal Somatostatin-Producing Neuroendocrine Tumor. NCI Thesaurus. Code C27407.

A somatostatin-producing neuroendocrine tumor that arises from the duodenum. It is characterized by the presence of tubulo-glandular structures. 